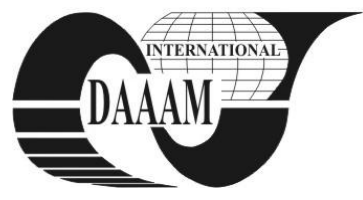

\title{
INTELLIGENT MONITORING AND STATISTICAL PROCESS CONTROL OF SURFACE ROUGHNESS ON CNC TURNING PROCESS
}

\author{
TANGJITSITCHAROEN, S[omkiat] \& RUNGRUANG, C[hannarong]
}

\begin{abstract}
In order to realize an intelligent machine tool, the aim of this research is to propose an integration of the inprocess monitoring and statistical process control of surface roughness during the turning process by using the cutting force ratio. The previously developed in-process surface roughness models of the author are adopted and employed to predict the surface roughness during the cutting with six factors of the cutting speed, the feed rate, the tool nose radius, the depth of cut, the rake angle, and the cutting force ratio. The statistical process control of the in-process surface roughness model has been presented to monitor and control the in-process predicted surface roughness at $95 \%$ confident level.
\end{abstract}

Key words: turning, monitoring, surface roughness, cutting force, statistical process control

\section{INTRODUCTION}

As the intelligent machine tool is expected to be realized in the near future, it is therefore necessary to monitor and estimate the in-process surface roughness during the cutting. Hence, the in-process monitoring and estimation of surface roughness models of the author are adopted and utilized in this research (Somkiat \& Angsumalin, 2010).

The statistical process control (SPC) is generally used to measure the capability of the process. However, the process capability of the cutting performance, such as the surface roughness which is based on the cutting conditions, depends on the states of cutting. It is therefore desirable to know the capability of the turning process referring to the in-process predicted surface roughness during the cutting. Hence, the fully integrated monitoring system and SPC of surface roughness for intelligent $\mathrm{CNC}$ turning machines is expected to be realized in the near future as shown in Fig. 1.

Extensive research efforts have been devoted so far to develop the surface roughness models (Sahin \& Motorcu, 2008; Lalwani et al., 2008). The effects of the cutting conditions are studied and investigated for the models (Cakir et al., 2009; Davim et al., 2008).

The ratio of the cutting forces is proposed to estimate the surface roughness because it is not sensitive to the variation of the cutting conditions in its components. The proposed dimensionless cutting force ratio consists of the main cutting force $F_{z}$ as the denominator and the feed force $F_{y}$ as the numerator.

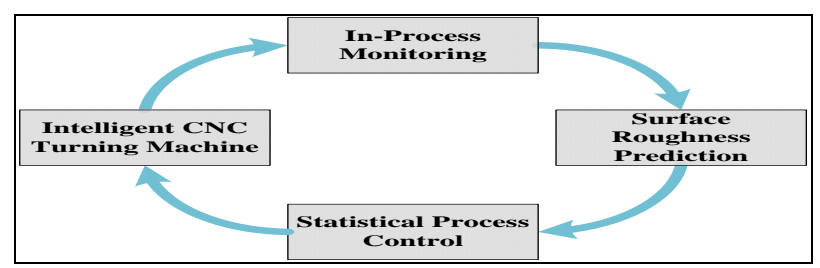

Fig. 1. Integration of in-process monitoring and statistical process control of surface roughness for intelligent $\mathrm{CNC}$ turning machine
The aim of this research is to propose a system to integrate the in-process monitoring of surface roughness and the inprocess statistical process control of surface roughness which can be used in practice. The in-process estimation on surface roughness models are adopted from the previous research of the author by monitoring the in-process cutting force ratio (Somkiat \& Angsumalin, 2010). The tool dynamometer is employed and utilized to measure the cutting force during the cutting.

\section{MONITORING AND STATISTICAL PROCESS CONTROL OF SURFACE ROUGHNESS}

\subsection{In-Process Prediction of Surface Roughness Model}

In order to estimate the in-process surface roughness during the cutting, the relations of the arithmetic average surface roughness $R_{a}$, the surface roughness $R_{Z}$, the cutting force ratio, and the cutting parameters are adopted from the previous research of the author as:

$$
\begin{aligned}
& R_{a}=53.52 \cdot v^{-0.122} \cdot f^{1.60} \cdot R_{n}{ }^{-0.519} \cdot D^{0.108} \cdot\left(\frac{F_{y}}{F_{z}}\right)^{-0.296} \cdot e^{-0.0187 \gamma} \\
& R_{z}=757.48 \cdot v^{-0.263} \cdot f^{1.59} \cdot R_{n}{ }^{-0.205} \cdot D^{0.163} \cdot\left(\frac{F_{y}}{F_{z}}\right)^{-0.18} \cdot e^{-0.00998 \gamma}
\end{aligned}
$$

The experimentally obtained in-process prediction of surface roughness models are valid at a high significance (Pvalue $=0.000)$ at $95 \%$ confident level. Therefore, the adopted models are reliable and usable to predict the in-process surface roughness of the arithmetic average surface roughness by utilizing the in-process monitoring system of the cutting force ratio with the cutting conditions of the cutting speed, the feed rate, the tool nose radius, and the depth of cut as the important predictors.

\subsection{Statistical Process Control of Surface Roughness}

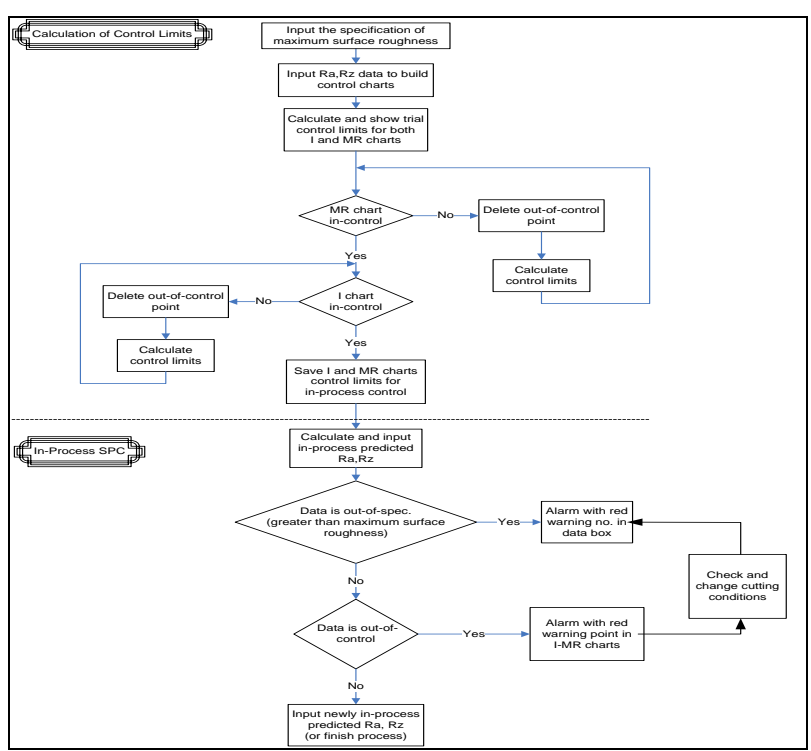

Fig. 2. Flowchart of in-process statistical process control of surface roughness 
The in-process statistical process control is developed and utilized to monitor the predicted surface roughness. The inprocess predicted surface roughness are fed in to the in-process SPC by employing the I-MR charts which normally use only one sample size to monitor the surface roughness. However, the initial control limits of the in-process predicted surface roughness have to be calculated and obtained firstly based on the actual data in order to use in the I-MR charts for the inprocess SPC afterwards. Normally, the calculated and obtained control limits are less than the specification required. Hence, the control limits which are the upper control limit (UCL) and the lower control limit (LCL) are calculated for the I-MR charts. The calculation procedures of the control limits for IMR charts and the use of the in-process SPC are shown in Fig. 2.

\section{EXPERIMENTAL CUTTING CONDITIONS AND PROCEDURES}

The cutting tests are conducted on a commercially available small CNC turning machine. The dynamometer is employed and installed on the turret of CNC turning machine in order to measure the in-process cutting forces. The carbon steel (AISI 1045) is adopted for the cutting experiments, and the cutting tools are the coated carbide tools (TNMG $160404 \mathrm{HQ}$, TNMG 160408 HQ, TPMR 160304 HQ, and TPMR 160308 HQ). The acceptable specifications of the surface of $\mathrm{Ra}$ and $\mathrm{Rz}$ are 5 and $20 \mu \mathrm{m}$, respectively.

The following procedures are adopted to predict the inprocess surface roughness and verify the in-process statistical process control of surface roughness during the actual cutting;

1) Develop the I-MR charts for the in-process statistical process control (in-process SPC) to monitor the in-process predicted surface roughness.

2) Calculate the upper control limit, UCL and the lower control limit, LCL of the arithmetic average surface roughness $R_{a}$ and the surface roughness $R_{Z}$, which are used in the I-MR charts.

3) Measure the cutting force ratios when the surface roughness is to be monitored, and calculate the predicted surface roughness from the in-process surface roughness model adopted.

4) Calculate and feed the predicted surface roughness obtained from the model into the in-process SPC which is developed to monitor the in-process predicted surface roughness on the I-MR charts.

5) Change the cutting conditions if the values of $R_{a}$ and $R_{Z}$ are out of the control limits of UCL and LCL until the values of $\mathrm{R}_{\mathrm{a}}$ and $\mathrm{R}_{\mathrm{Z}}$ are in the control limits of UCL and LCL.

\section{IN-PROCESS SURFACE ROUGHNESS PREDICTION AND CONTROL}

Fig. 3 shows the in-process SPC of the Ra and Rz by utilizing the I-MR Charts with the preliminary calculated UCL and LCL under the acceptable specification of the Ra and Rz which are 5 and $20 \mu \mathrm{m}$, respectively. The preliminary calculated control limits of UCL and LCL of the Ra and Rz whcih are calculated from the 33 cutting tests are used to monitor the in-process predicted surface roughness during the cutting. If the values of the $\mathrm{Ra}$ and $\mathrm{Rz}$ are out of the control limits of UCL and LCL, the alarm with the red point will appear and the cutting conditions, such as the feed rate and the depth of cut, will be checked and changed until the in-process predicted surface roughness is in the control limits of UCL and LCL as shown in Fig. 3.

Since the proposed model is developed from the actual cutting data with no any dummy level sets, it can be effectively used to predict the in-process surface roughness for any cutting condition while the others cannot. It is implied that the higher cutting performance and the better surface finish can be achieved which leads to the lower production cost and also the higher production rate.

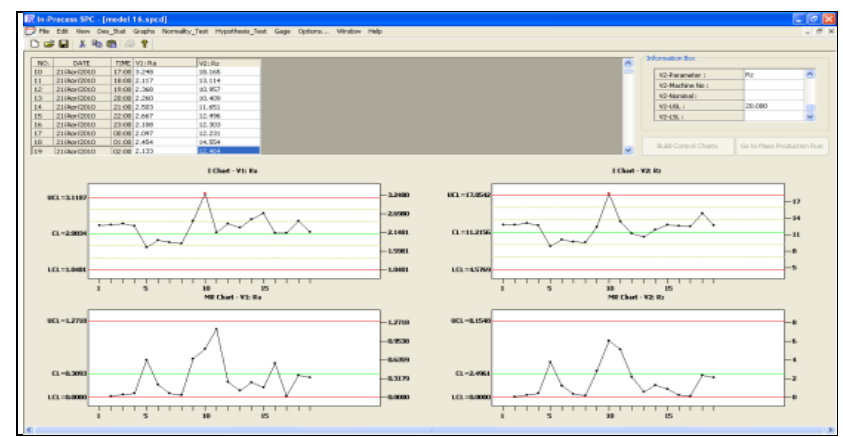

Fig. 3. Illustration of in-process statistical process control of surface roughness

\section{CONCLUSIONS}

An integration of in-process monitoring and statistical process control is proposed and developed to realize the intelligent $\mathrm{CNC}$ turning machine. The in-process monitoring is proposed to measure the cutting force ratio in order to predict the in-process surface roughness. It is proved by the cutting experiments that the in-process surface roughness can be predicted and obtained with the high accuracy by using the inprocess surface roughness models proposed.

The largest potential advantage of the method proposed here is that the in-process statistical process control can be utilized to check and control the in-process predicted surface roughness during the actual cutting referring to the upper and lower control limits of the surface roughness in I-MR Charts.

\section{ACKNOWLEDGEMENTS}

This research was performed and supported by The Thailand Research Fund (TRF) from March 2009 to March 2011.

\section{REFERENCES}

Cakir, M. C.; Ensarioglu, C. \& Demirayak, I. (2009). Mathematical models of surface roughness for evaluating the effects cutting parameters and coating materials. Journal of Materials Processing Technology, Vol. 209, No. 1, (January 2009), pp. 102-109, ISSN: 0924-0136

Davim, J. P.; Gaitonde, V. N. \& Karnik, S. R. (2008). Investigations into the effect of cutting conditions on surface roughness in turning of free machining steel by ANN models. Journal of materials processing technology, Vol. 205, (August 2008), pp. 16-23, ISSN: 0924-0136

Lalwani, D. I.; Mehta, N. K. \& Jain, P .K. (2008). Experimental investigation of cutting parameters influence on cutting forces and surface roughness in finish hard turning of MDN250 steel. Journal of materials processing technology, Vol. 206, No. 1-3, (September 2008), pp. 167-179, ISSN: 0924-0136

Sahin, Y. \& Motorcu, A. R. (2008). Surface roughness model in machining hardened steel with cubic boron nitride cutting tool. Journal of Refractory Metals \& Hard Materials, Vol. 26, (March 2008), pp. 84-90, ISSN: 0263-4368

Somkiat, T. \& Angsumalin, S. (2010). Monitoring of surface roughness in CNC Turning Process, Annals of DAAAM for 2010 \& Proceeding of the $21^{\text {st }}$ International DAAAM Symposium, Vol. 21, No. 1, ISSN: 1726-9679, ISBN:978-3901509-73-5, Katalinic, B. (Ed.), pp. 1391-1392, DAAAM International, Vienna, Austria 